\title{
Article \\ Bioguided Phytochemical Study of Ipomoea cairica Extracts with Larvicidal Activity against Aedes aegypti
}

\author{
Víctor Álvarez Valverde ${ }^{1,2, *}$, Gerardo Rodríguez Rodríguez ${ }^{2}$ and Silvia Argüello Vargas ${ }^{1}$ (D) \\ 1 Programa Regional en Ciencias Veterinarias Tropicales, Escuela de Medicina Veterinaria, \\ Universidad Nacional, Heredia 40101, Costa Rica; silvia.arguello.vargas@una.cr \\ 2 Laboratorio de Fitoquímica, Escuela de Química, Universidad Nacional, Heredia 40101, Costa Rica; \\ lafit@una.ac.cr \\ * Correspondence: victor.alvarez.valverde@una.ac.cr
}

Citation: Álvarez Valverde, V.; Rodríguez Rodríguez, G.; Argüello Vargas, S. Bioguided Phytochemical Study of Ipomoea cairica Extracts with Larvicidal Activity against Aedes aegypti. Molecules 2022, 27, 1348 https://doi.org/10.3390/molecules 27041348

Academic Editor: Riccardo Petrelli

Received: 9 December 2021

Accepted: 3 February 2022

Published: 16 February 2022

Publisher's Note: MDPI stays neutral with regard to jurisdictional claims in published maps and institutional affiliations.

Copyright: (C) 2022 by the authors. Licensee MDPI, Basel, Switzerland. This article is an open access article distributed under the terms and conditions of the Creative Commons Attribution (CC BY) license (https:// creativecommons.org/licenses/by/ $4.0 /)$.

\begin{abstract}
Vector-borne diseases, such as those transmitted by Aedes aegypti, are a constant threat to inhabitants of tropical regions of the planet. Synthetic chemicals are commonly used as a strategy to control them; however, these products are known to persist in ecosystems and drive the appearance of resistance genes in arthropod vectors. Thus, the use of natural products has emerged as an environmentally friendly alternative in integrated vector control strategies. The present bioguided study investigated the larvicidal potential of Ipomoea cairica extracts, fractionated using thin-layer and open-column chromatography, because this species has been shown to exert larvicidal effects on the genus Aedes. The objective of this study was to evaluate the nonvolatile components in ethanolic extract of I. cairica stems as a potential natural larvicidal, and coumarins, such as 7-hydroxy6-methoxychromen-2-one (scopoletin) and 7-hydroxychromen-2-one (umbelliferone), were identified as major compounds; however, they were not shown to be responsible for the larvicidal activity. Based on the results of the larvicidal action tests, these coumarins are not directly responsible for the larvicidal activity, but this activity might be attributed to a synergistic effect of all the compounds present in the most active secondary fraction, called F.DCM, which had an $\mathrm{LC}_{50}$ value of $30.608 \mathrm{mg} / \mathrm{L}$. This type of study has yet not been conducted in the region; therefore, it is an important contribution to recognizing a natural and easy-to-cultivate source of vector control, such I. cairica.
\end{abstract}

Keywords: chromatography; coumarins; secondary metabolites; organic extracts

\section{Introduction}

Aedes aegypt $i$ is one of the most important vectors for the transmission of viral diseases, including dengue, Zika, chikungunya, yellow fever, and Mayaro [1-3]. In Costa Rica, 9438 cases of dengue were diagnosed (at epidemiological week 44) in 2020, and since 2010, more than 185,471 cumulative cases have been reported [4]. The chemical control of arthropod vectors has been used as an emergency strategy in the event of outbreaks; however, synthetic products, such as organophosphates, pyrethroids, and carbamates, are nonspecific and exhibit poor water solubility-they persist in ecosystems, and their inadequate use has caused the appearance of resistance in vectors in different parts of the world. Therefore, the use of natural larvicides has emerged as an alternative for the control of arthropod vectors, since natural secondary metabolites with multiple bioactivities, including larvicidal activities, have been identified and are reincorporated into ecosystems once their function is fulfilled [5-11]. Eco-friendly and effective mosquitocidal extracts have the cumulative advantages of being cost effective, environmentally benign, safe to nontarget organisms, and biodegradable [10].

Numerous studies have shown the contributions of essential oils and volatile fractions of plants as mosquito larvicides or repellents using specific extraction methods for this type of metabolite [10,12-14]. Nevertheless, few studies have focused on the nonvolatile 
fractions of plants. Since all the compounds have different functions in plants, an interesting approach is to study the nonvolatile fractions of plants with the aim of identifying some important bioactivities, such as larvicidal activity. Nevertheless, the scientific community must acknowledge the importance of research into bioinsecticides and their roles preventing the appearance of resistance.

Ipomea cairica, commonly known as morning glory, is an extremely common plant in tropical climates that is known for its rapid growth and abundant spread, and it is mainly used for ornamental purposes. It contains diverse secondary metabolites with reported bioactivities, including larvicidal, anticancer, antimicrobial, antinociceptive, and cytotoxic activities [5-7,9,15-17]. A preliminary study determined that, of a set of 14 plants found in Costa Rica, 5 showed larvicidal activity against $A$. aegypti, with the ethanolic extract of I. cairica stems representing the most lethal extract toward $A$. aegypti, with a $50 \%$ lethal concentration $\left(\mathrm{LC}_{50}\right.$ ) of $0.0341 \mathrm{mg} / \mathrm{mL}$ and a $95 \%$ confidence interval of $0.0293-0.0393 \mathrm{mg} / \mathrm{mL}$ [13] The objective of the current project was to evaluate the nonvolatile components in the ethanolic extract of I. cairica stems as potential natural larvicidal agents.

\section{Results}

Table 1 shows the larvicidal activity of the ethanolic extracts of stems and leaves. The ethanolic extract of I. cairica stems produced $71.3 \%$ mortality, and that of leaves produced $40.0 \%$ mortality. This observation is consistent with the findings of a preliminary study [15] Since the ethanolic extract of leaves was not as promising as that of stems in terms of biological activity, the present study focused solely on I. cairica stems.

Table 1. Larvicidal activity of the ethanolic extracts of I. cairica stems and leaves.

\begin{tabular}{cc}
\hline Sample & Percent Mortality at 24 h \\
\hline Stems & $71.3 \pm 4.8 \%$ \\
\hline Leaves & $40.0 \pm 0.0 \%$ \\
\hline Positive control & $100 \pm 0 \%$ \\
\hline Negative control & $0 \pm 0 \%$ \\
\hline
\end{tabular}

The larvicidal activity of the ethanolic stem extract and its increasingly polar fractions obtained using column chromatography (CC) are shown in Table 2. When applied at $100 \mathrm{mg} / \mathrm{L}$, the crude ethanolic extract of I. cairica stems presented a relatively high larvicidal activity of $71.3 \%$ mortality. The acetone fraction (F.Ac) showed a low percentage of mortality, and hexane (F.He) and methanol (F.Me) fractions showed no larvicidal activity. In contrast, the dichloromethane fraction (F.DCM) showed 100\% mortality when tested under similar conditions.

Table 2. Larvicidal activity of the ethanolic extract and its increasingly polar fractions obtained using CC.

\begin{tabular}{cc}
\hline Sample & Percent Mortality at 24 h \\
\hline Crude ethanolic extract & $71.3 \pm 4.8 \%$ \\
\hline F.He & $0 \pm 0 \%$ \\
\hline F.DCM & $100 \pm 0 \%$ \\
\hline F.Ac & $18.8 \pm 2.9 \%$ \\
\hline F.Me & $0 \pm 0 \%$ \\
\hline Positive control & $100 \pm 0 \%$ \\
\hline Negative control & $0 \pm 0 \%$ \\
\hline F-fraction; He-hexane; DCM-dichloromethane; Ac—acetone; Me-methanol.
\end{tabular}


Figure 1 shows the thin-layer chromatography (TLC) analysis of the samples reported in Table 2. Each column numbered from 1 to 5 corresponds to a different sample, which moves from bottom to top with the mobile phase, allowing the separation of the compounds. Sample 1 is the original extract, and fractions $2-5$ correspond to secondary fractions obtained with different solvents from a chromatographic column of the original ethanolic extract. TLC facilitated the separation of most of the compounds present in each evaluated sample. The TLC plate was visualized with ultraviolet light at a wavelength of $365 \mathrm{~nm}$, and the absorption at these wavelengths indicates the presence of aromatic rings and/or conjugated double bonds in the structure of the metabolite. The band marked with the red arrow in Figure 1A indicates the presence of a metabolite with functional groups similar to those mentioned above. As the band intensity increased (Figure 1B) by spraying the plate with a base, such as $\mathrm{KOH}$, the metabolite is highly probable to be a coumarin. Based on this information, we predicted that the secondary metabolites present in the samples run on this plate are very similar in terms of their chemical structure, and that at least two are coumarins.
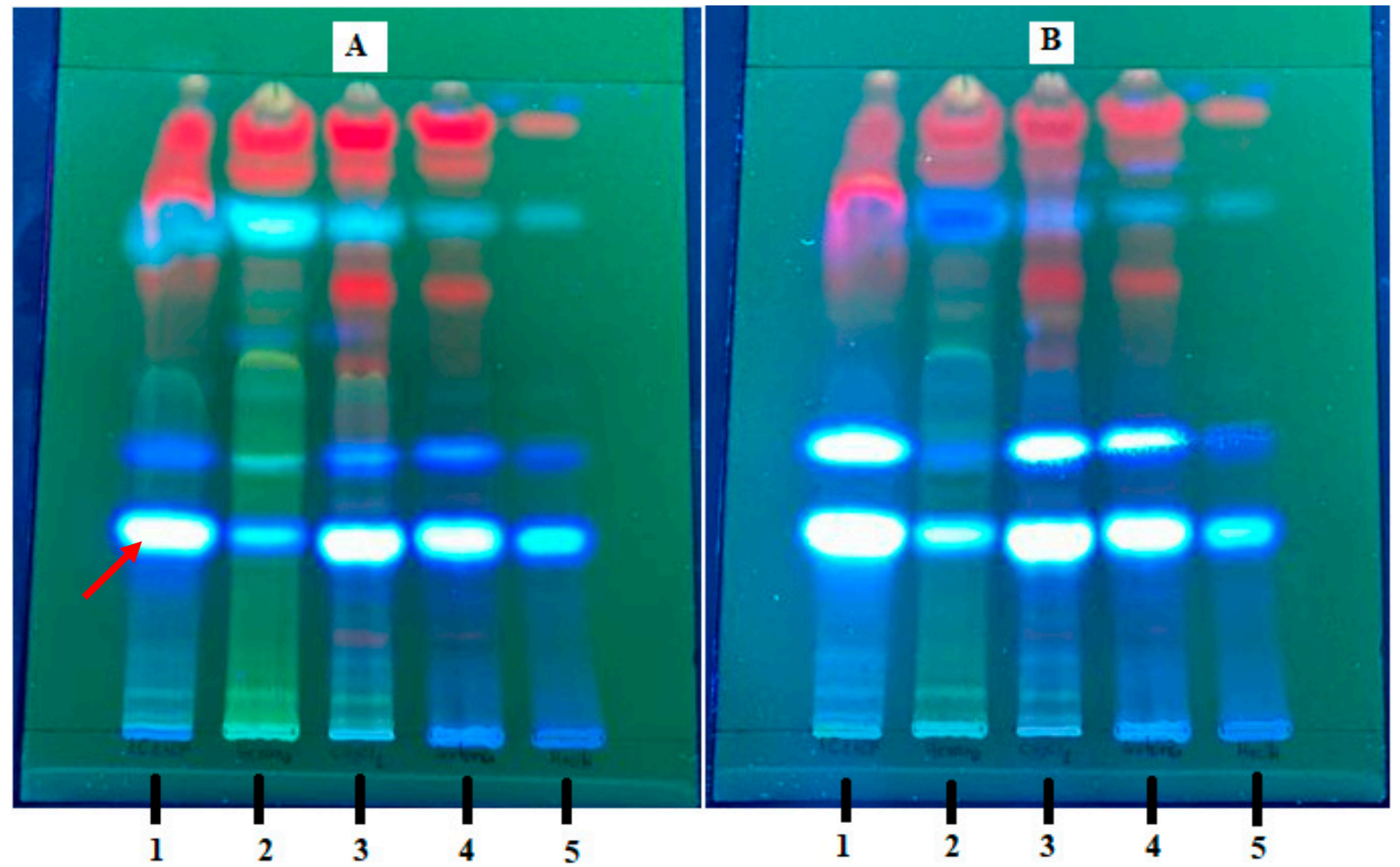

Figure 1. Thin-layer chromatography of the fractions listed in Table 3 that were evaluated for larvicidal activity visualized with UV light at $365 \mathrm{~nm}(\mathbf{A})$ and with $\mathrm{KOH}$ in ethanol (B); 1-crude extract in Et; 2-F.He; 3-F.DCM; 4-F.Ac; 5-F.Me.

The major compounds in the F.DCM were separated using preparative TLC, and each secondary fraction of the F.DCM was evaluated for larvicidal activity. All bioassays conducted with 100 ppm of the F.DCM showed larvicidal activity with 100\% mortality; however, the subsequent fractionation of the F.DCM caused an absolute loss of larvicidal activity (Table 3 ). 
Table 3. Larvicidal activity of the F.DCM and its secondary fractions (1, 2, and 3$)$ obtained using preparative TLC.

\begin{tabular}{cc}
\hline Sample & Percent Mortality at $\mathbf{2 4} \mathbf{h}^{*}$ \\
\hline F.DCM & $100 \pm 0 \%$ \\
\hline F.DCM (1) & $0 \pm 0 \%$ \\
\hline F.DCM (2) & $0 \pm 0 \%$ \\
\hline F.DCM (3) & $0 \pm 0 \%$ \\
\hline Positive control & $100 \pm 0 \%$ \\
\hline Negative control & $0 \pm 0 \%$ \\
\hline
\end{tabular}

${ }^{*}$ Mean values of four replicates.

Table 4 shows the results of the larvicidal activity of the F.DCM and that of the crude ethanol extract of the stems of I. cairica. The mean $\mathrm{LC}_{50}$ values were lower for the F.DCM than for the ethanolic extract of stems.

Table 4. Results of the larvicidal activity of the F.DCM and crude ethanolic extract.

\begin{tabular}{|c|c|c|c|}
\hline Fraction & $\mathrm{LC}_{50}$ in $\mathrm{mg} / \mathrm{L}(95 \% \mathrm{CI} *)$ & $\begin{array}{l}\mathrm{LC}_{90} \text { in } \mathrm{mg} / \mathrm{L} \\
(95 \% \mathrm{CI} *)\end{array}$ & $\begin{array}{c}\text { Diagnostic Dose in } \mathrm{mg} / \mathrm{L} \\
(95 \% \mathrm{CI} *)\end{array}$ \\
\hline F.DCM & $\begin{array}{c}30.608 \\
(23.9-39.1)\end{array}$ & $\begin{array}{c}79.875 \\
(62.5-98.1)\end{array}$ & $\begin{array}{c}349.2 \\
(273.1-446.4)\end{array}$ \\
\hline Crude ethanolic extract & $\begin{array}{c}42.1 \\
(32.1-55.0)\end{array}$ & $\begin{array}{c}131 \\
(100.0-172.0)\end{array}$ & $\begin{array}{c}664 \\
(507-870)\end{array}$ \\
\hline
\end{tabular}

${ }^{*} \mathrm{CI}-$ confidence interval; $\mathrm{LC}_{90}-90 \%$ lethal concentration.

Figure 2 shows the larvicidal activity of the F.DCM and crude ethanolic extract (CE-Et) at different concentrations. At a $95 \% \mathrm{CI}$ in each curve, the mortality response differed between the F.DCM and EC-Et. For a particular concentration ranging from 0 to $200 \mathrm{ppm}$, the observed percent mortality induced by the F.DCM was higher than that of EC-Et.

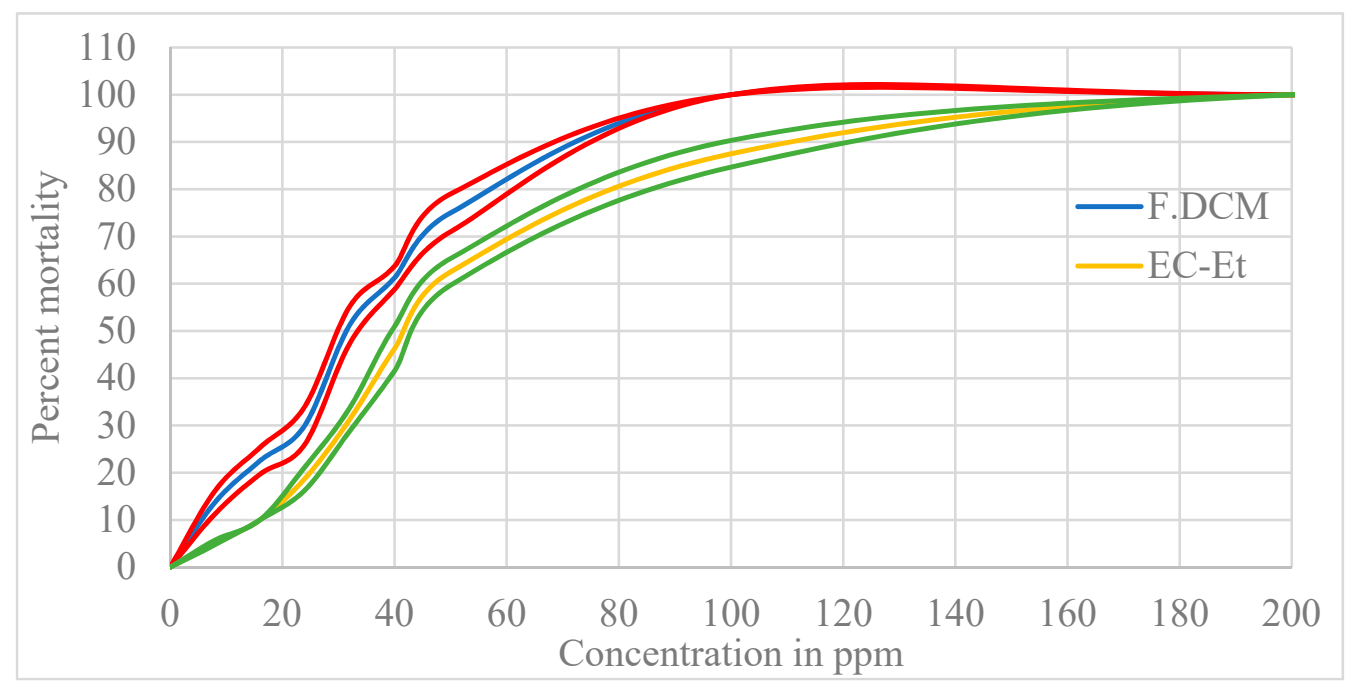

Figure 2. Observed percent mortality according to the sample concentration for the F.DCM and CE-Et shown in blue and yellow, respectively; the red and green lines indicate the expected mortality at the 95\% CI.

In Figure 3, two blue bands were observed for the F.DCM when the plate was visualized under UV light at $365 \mathrm{~nm}$, which were intensified when the plate was sprayed with $10 \% \mathrm{KOH}$ in ethanol. This result indicates the presence of coumarins in the plant stem. 


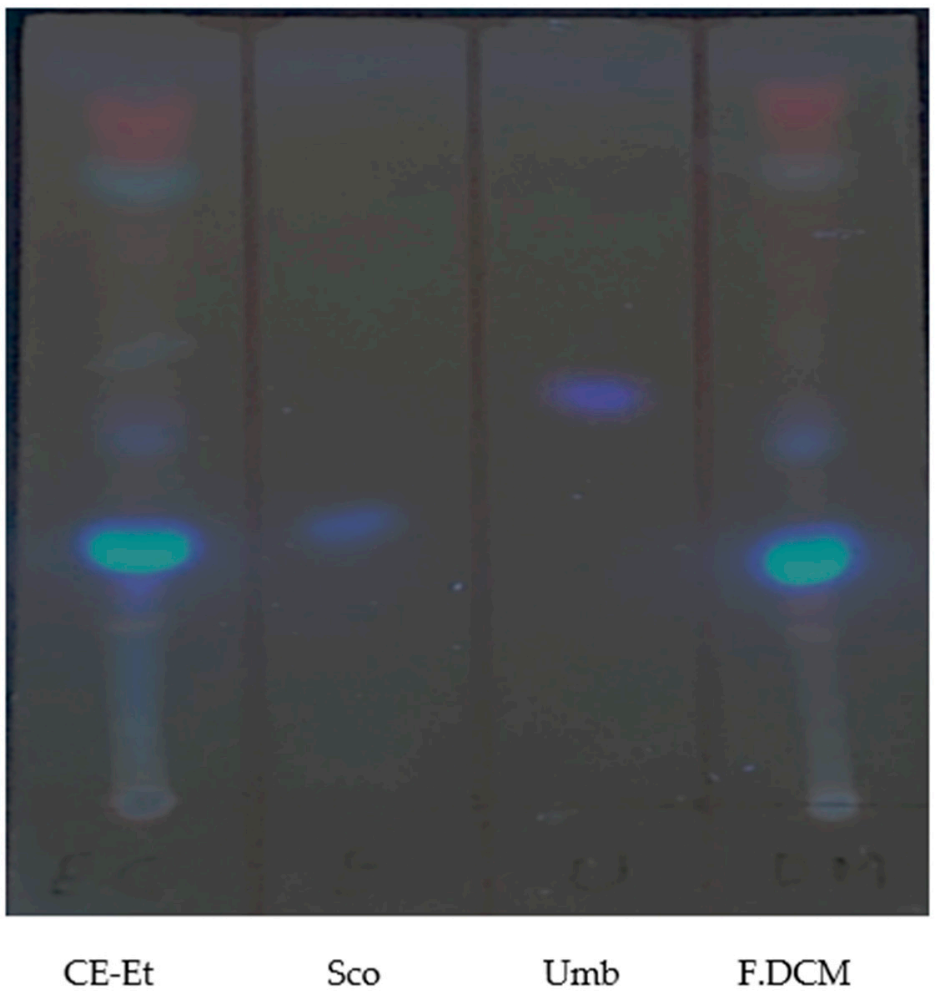

Figure 3. TLC plate eluted with toluene:ether (1:1) saturated with $10 \%$ acetic acid and developed with $5 \% \mathrm{KOH}$ in ethanol; CE-Et—crude extract in ethanol; Sco-scopoletin standard; Umb-umbelliferone standard; F.DCM-dichloromethane secondary fraction.

Figure 4 shows the high-performance liquid chromatography (HPLC) chromatograms, recorded at 2 wavelengths: $280 \mathrm{~nm}$, typical for molecules with aromatic rings, and $343 \mathrm{~nm}$, which exclusively detects a few secondary metabolites, including coumarins. Each peak in the chromatogram represents a compound, indicating that the F.DCM consists of relatively few compounds, three of which are potentially coumarins.

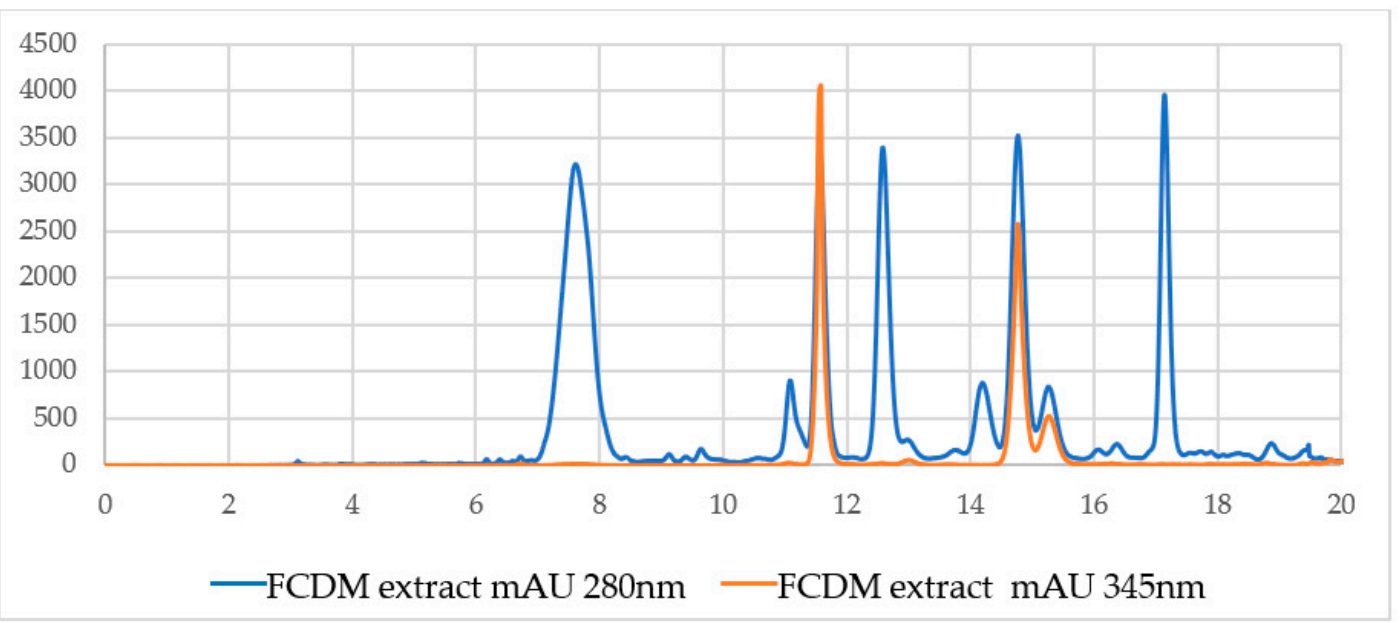

Figure 4. Reverse-phase HPLC diode array detector (DAD) chromatograms of the F.DCM obtained at 2 wavelengths, $280 \mathrm{~nm}$ and $343 \mathrm{~nm}$.

As part of the process used to identify at least 2 secondary metabolites present in the active secondary DCM fraction, the signals or peaks present at 11.8 and 14.9 min in the chromatogram shown in Figure 4 were isolated, corresponding to the major peaks that 
absorb at $343 \mathrm{~nm}$. The result of the isolation of the major peaks presented in the F.DCM that absorbs at $343 \mathrm{~nm}$ is shown in pure form in Figures 5 and 6.

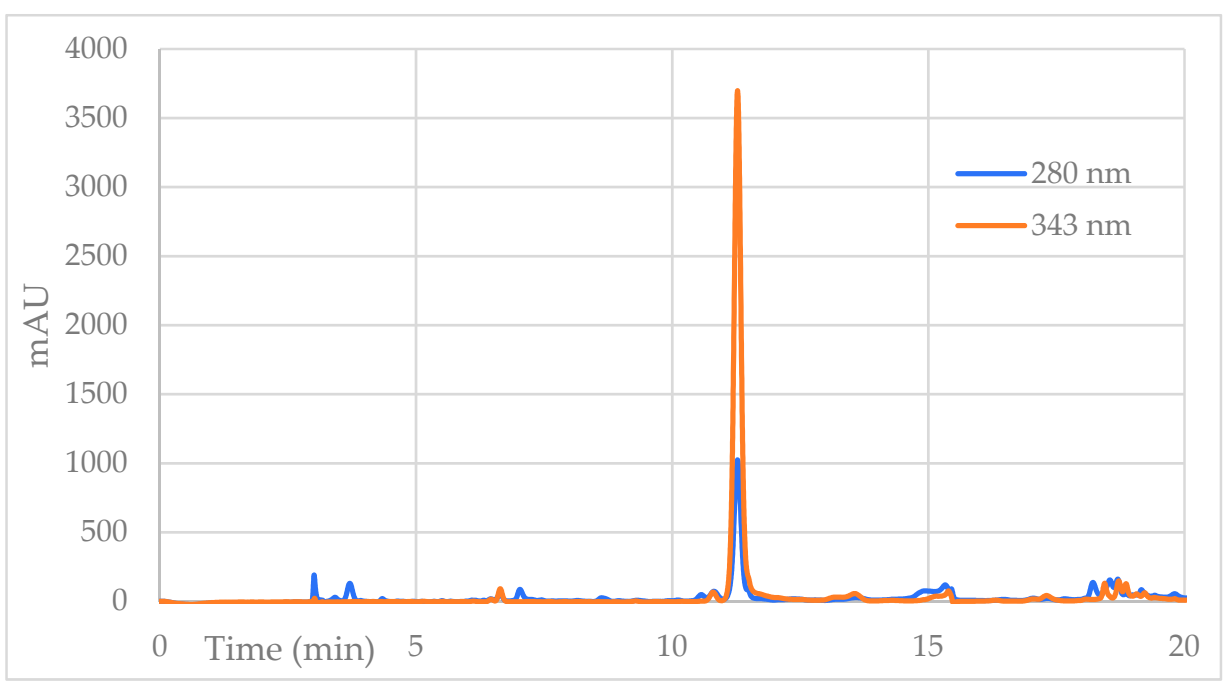

Figure 5. Reverse-phase HPLC-DAD chromatogram of the first purified compound at 2 wavelengths, $280 \mathrm{~nm}$ and $343 \mathrm{~nm}$.

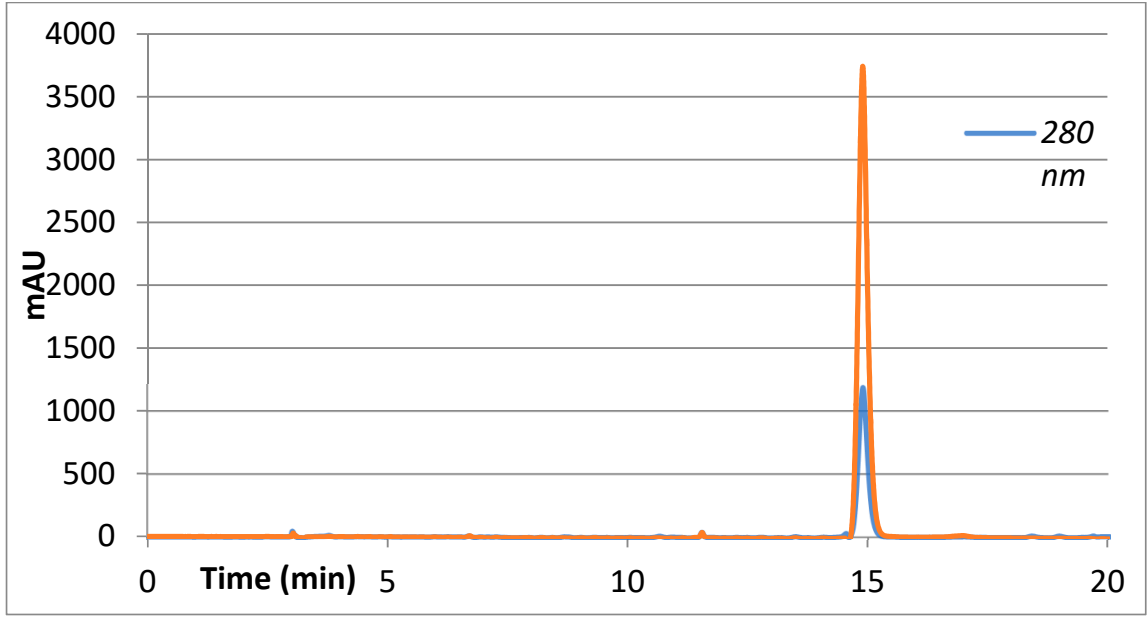

Figure 6. Reverse-phase HPLC-DAD chromatogram of the second purified compound at 2 wavelengths, $280 \mathrm{~nm}$ and $343 \mathrm{~nm}$.

The HPLC chromatograms in Figure 7 show the agreement of the retention times between the standards of the 2 coumarins (B and C) and the F.DCM (A) under the same chromatographic conditions and at wavelengths of 280 and $343 \mathrm{~nm}$. 

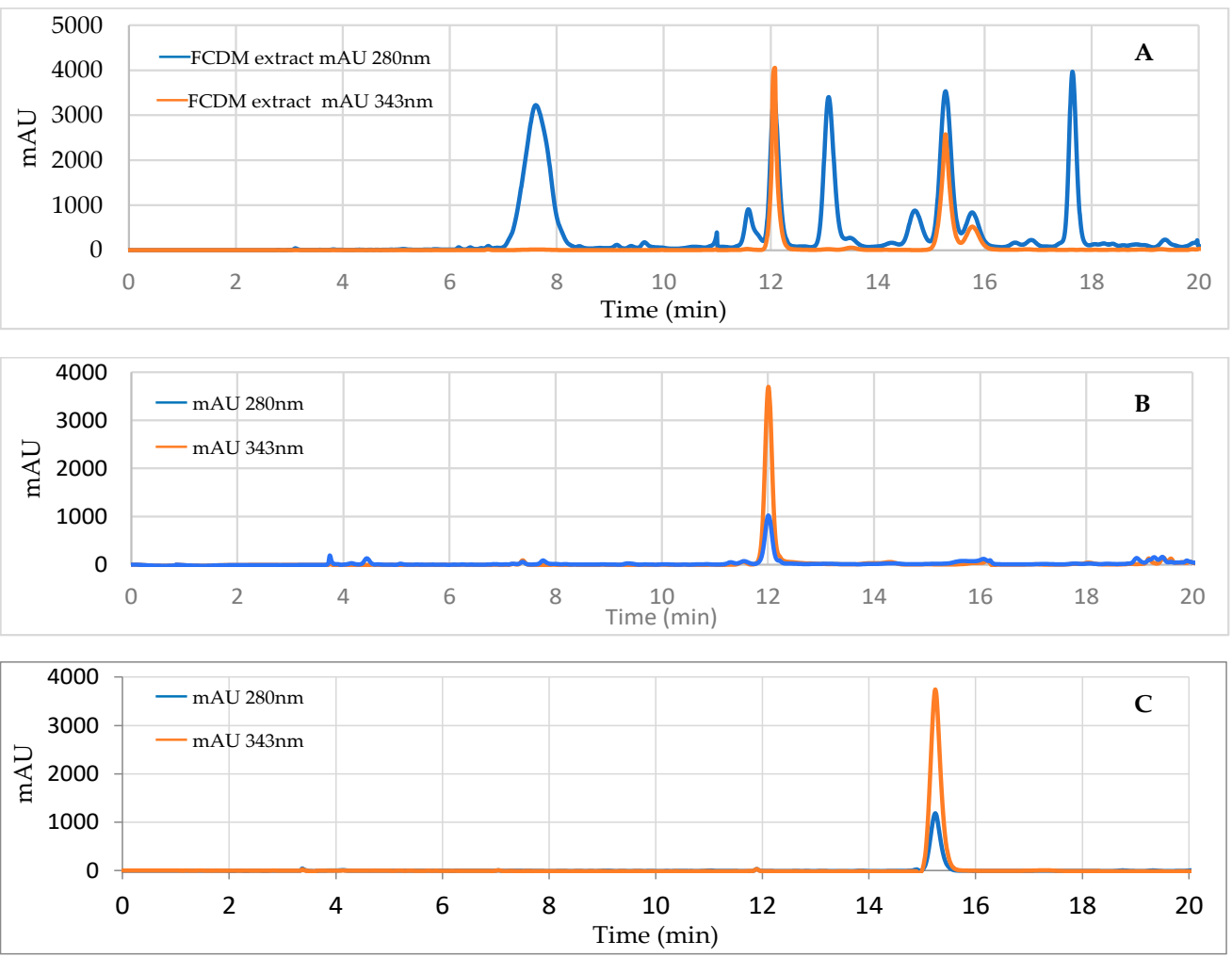

Figure 7. Reverse-phase HPLC-DAD chromatogram of the active F.DCM (A), scopoletin standard (B), and umbelliferone standard (C), at 2 wavelengths, 280 and $343 \mathrm{~nm}$.

Figures 8 and 9 show the mass spectra of the two coumarins obtained from I. cairica stems. The mass spectra of the molecular ion were generated using this analysis in positive mode, i.e., the molecular weight of the +1 molecule, which in some cases may generate a series of additional peaks corresponding to various molecular fragments, as shown in Figure 8. This same figure shows the molecular ion at $m / z 163$, which corresponds to the molecular weight of the coumarin umbelliferone +1 . Figure 9 shows a molecular ion at $\mathrm{m} / z$ 193, which corresponds to the molecular weight of the coumarin scopoletin +1 .

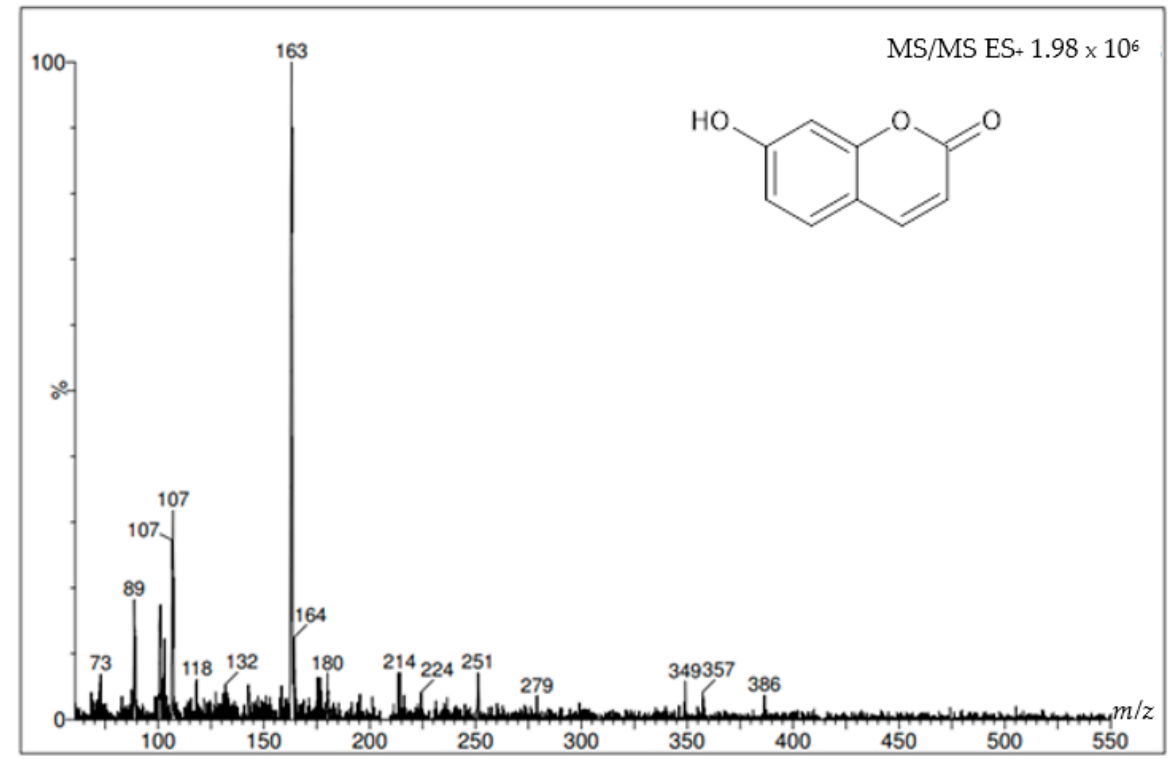

Figure 8. Mass spectrum with the molecular ion of the coumarin umbelliferone using HPLC-MS/MS spectrometer. 


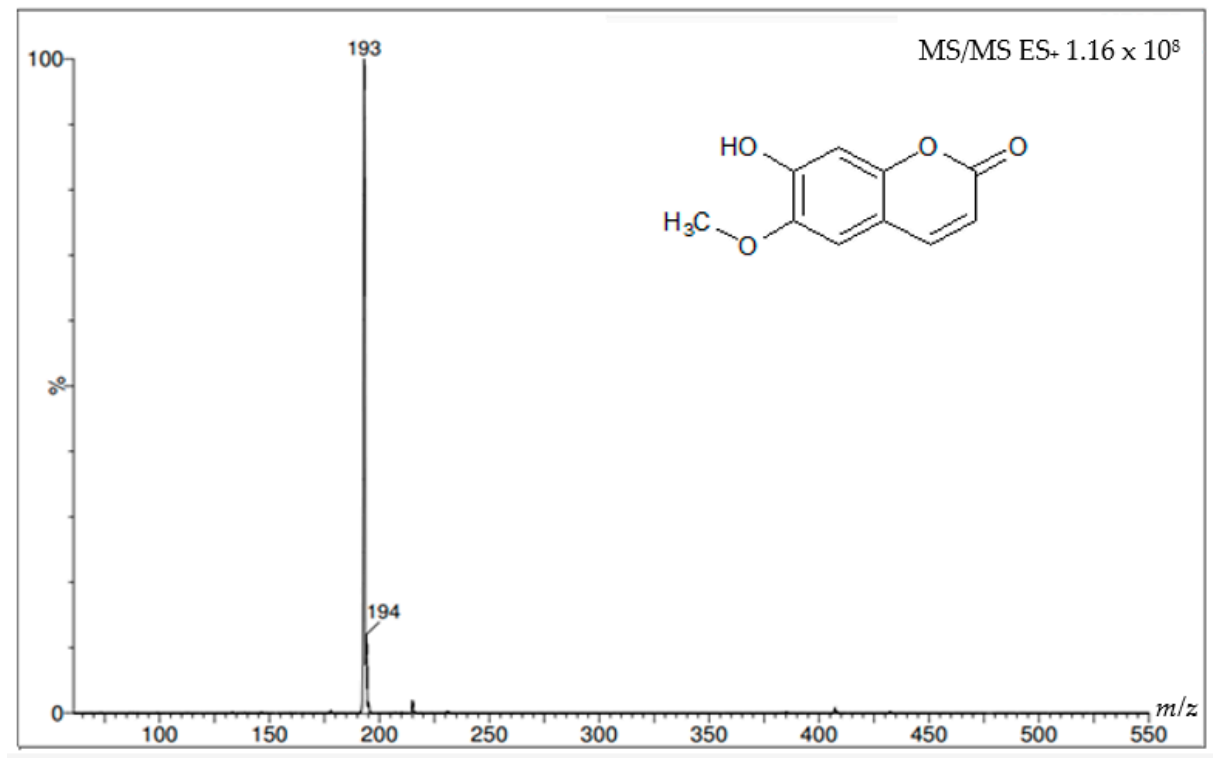

Figure 9. Mass spectrum with the molecular ion of the coumarin scopoletin HPLC-MS/MS spectrometer.

The evaluation of the larvicidal activity of the coumarins was negative, suggesting that this activity might be related to the synergistic activities of all the compounds present in the F.DCM (Table 5).

Table 5. Larvicidal activity of the isolated pure compounds scopoletin and umbelliferone, and of a combination of both compounds, isolated from the plant I. cairica. The test was performed with 4 homogeneous replicates of $n=80$ larvae.

\begin{tabular}{cc}
\hline Sample & Percent Mortality \\
\hline Scopoletin & 0 \\
\hline Umbelliferone & 0 \\
\hline Scopoletin + Umbelliferone & 0 \\
\hline CONTROL+ & 100.00 \\
\hline CONTROL - & 0.00 \\
\hline
\end{tabular}

\section{Discussion}

A preliminary study of larval mortality allowed us to establish the different larvicidal activities of ethanolic extracts of I. cairica stems and leaves [15], as shown in this study, where the ethanolic stem extract of this plant produced $71.3 \%$ mortality and the leaf extract produced $40.0 \%$ mortality. The photosynthetic tissues of plants are more concentrated in the leaves than in stems, and these tissues are extracted when in contact with organic solvents, such as ethanol. The resulting extract is rich in secondary metabolites and photosynthetic pigments, such as chlorophylls and xanthophylls, which not only hinder the separation of a particular secondary metabolite but also dilute the possible biological activity. In the present study, the ethanolic leaf extract was not as promising as the stem extract in terms of biological activity.

The crude ethanolic extract of I. cairica stems presents a relatively high larvicidal activity at $100 \mathrm{mg} / \mathrm{L}$, with $71.3 \%$ mortality, compared with the larvicidal mortality data reported by Srivastava and Shukla (2015), who indicated that an essential oil extract of this plant achieves up to $100 \%$ mortality in $24 \mathrm{~h}$ when evaluated at $120 \mathrm{mg} / \mathrm{L}$. Additionally, Chariandy et al. (1999) obtained positive mortality results 2 days after initiating the test by exposing stage IV A. aegypti larvae to $500 \mathrm{mg} / \mathrm{L}$ of an ethyl acetate extract of Justicia pectoralis for $1 \mathrm{~h}$, ensuring that larvicidal activity was present in the initial extract before fractionation. The F.He and F.Me showed no larvicidal activity. In contrast, the F.DCM 
showed a mortality rate of $100 \%$ of the individuals when tested under conditions similar to the other samples. The low percent mortality of the F.Ac indicates that very few of the active secondary metabolites were eluted with this solvent, while none of these compounds were eluted by Me and $\mathrm{He}$.

According to Ahbirami et al. (2014), I. cairica leaves have larvicidal activity against $A$. albopictus and $A$. aegypti when extracted with acetone or methanol, showing $\mathrm{LC}_{50}$ values of $101.94 \mathrm{mg} / \mathrm{L}$ and $105.50 \mathrm{mg} / \mathrm{L}$, respectively, for A. aegypti [8]. The study by Ahbirami et al. is fundamental because it provides evidence that I. cairica possesses potential larvicidal activity; however, this study did not delve into different phytochemical approaches to determine whether acetone or methanol is the most appropriate solvent to extract the secondary metabolites responsible for larvicidal activity. An important difference between the extraction process used by Ahbirami et al. (2014) and the one performed in the present study must be noted. The difference lies in the extraction temperature, which several studies report to be a factor that must be meticulously regulated to improve the chemical integrity of the extract when temperatures no higher than $40{ }^{\circ} \mathrm{C}$ are used. Ahbirami et al. used temperatures up to $60^{\circ} \mathrm{C}$ for at least $3 \mathrm{~h}$; whereas, in the present study, the necessary precautions were taken not to exceed $40{ }^{\circ} \mathrm{C}$, thus generating a possible fundamental difference in the extract composition $[15,16]$.

Based on the results, the F.DCM comprises a combination of secondary metabolites that would be present in the crude ethanolic extract. The ethanolic extract contains a greater number of metabolites, some of which do not possess larvicidal activity. As a result, bioactive metabolites are present at a lower concentration in the EC-Et, which results in a lower bioactivity compared with the F.DCM.

The F.DCM showed 2 blue bands when visualizing the chromatographic plate under UV light at $365 \mathrm{~nm}$, which were intensified when the plate was sprayed with $10 \% \mathrm{KOH}$ in ethanol. This result indicates the presence of coumarins in the stem of the plant. Meira et al. (2012) [18] described the presence of two coumarins, 7-hydroxy-6-methoxychromen-2-one (scopoletin) and 7-hydroxychromen-2-one (umbelliferone), in the dichloromethane extract of I. cairica. These coumarins are identified by their retention factors (rf) of 0.25 and 0.45 , respectively [19], which are within the range obtained in this study.

The similar retention times of the peaks of the standards and the peaks present in the HPLC chromatogram of the F.DCM suggests that the coumarins are scopoletin and umbelliferone. HPLC-mass spectrometry (MS) was used to verify this identification and showed that the molecular weights of the coumarins were consistent with those reported in the literature: $162.14 \mathrm{~g} / \mathrm{mol}$ for umbelliferone [20] and $192.16 \mathrm{~g} / \mathrm{mol}$ for scopoletin [21].

The evaluation of the larvicidal activity revealed no activity of these coumarins, suggesting that the larvicidal activity might be related to the synergistic effects of the components of the F.DCM. This larvicidal activity of the F.DCM was detected at relatively low concentrations compared with other studies [22,23]. An in silica study by Rollinger et al. (2004), analyzing approximately 110,000 molecules, suggests that analogs of scopoletin and its glycosylated homolog, scopoline, are notable as possible inhibitors of acetyl cholinesterase (ACh) [24], which is the same mechanism of action as organophosphates, such as temephos, used as larvicides in vector control [25]. Another recurring mechanism of action of nonpolar molecules is the suppression of adenosine triphosphate (ATP), which may be due to partial competition with nicotinamide adenine dinucleotide (NADH)-ubiquinone oxidoreductase [26,27]. A potential explanation for this finding is that F.DCM is enriched in components with a partially nonpolar profile that are present in the crude extract, and the structures of some of these molecules might have stereochemistry surrounding cycles that contribute to larval death [27]. Importantly, molecules that exhibit bioactivity must have target site specificity, which, in some cases, might be potentiated in the presence of synergistic components in the matrix [28]. Regarding natural larvicidal products, synergistic effects are commonly reported for volatile plant extracts [29-31] and sometimes for nonvolatile extracts [26,32]. In addition, plant molecules usually present low 
toxicity to mammals, and they are nontoxic to humans and other nontarget organisms at the recommended doses [33].

Because of both the thoroughness of the purification process and the larvicidal tests performed here, the larvicidal activity of the extracts and fractions obtained from the I. cairica stems were confirmed to have a comparatively high lethality with respect to other nonvolatile extracts of natural products evaluated against $A$. aegypti larvae $[6,16,34]$. Additionally, the larvicidal activity was not attributed to the pure compounds isolated from the active fractions; rather, this bioactivity was attributed to a synergistic effect of the set of compounds present in the ethanolic extract and those purified from the ethanolic extract present in F.DCM. Therefore, further studies are needed to corroborate whether the observed activity is linked to synergism. Additionally, this type of study has not yet been conducted in the region; therefore, it is an important contribution to recognizing a natural and easy-to-cultivate source of vector control-I. cairica.

\section{Materials and Methods}

The methodology described in the present study is based on a bioguided design, where the processes used to separate and purify components are based on the result of the larvicidal activity observed for each extract evaluated.

\subsection{Plant Material}

The sample was collected in San Miguel de Santo Domingo de Heredia, Costa Rica (permit no. R-012-2020-OT-CONAGEBIO). The leaves were separated from the stems, and both plant parts were dried in a convection oven at $40{ }^{\circ} \mathrm{C}$ for $72 \mathrm{~h}$. Once dry, they were ground in a knife mill using a $1 \mathrm{~mm}$ sieve.

\subsection{Sample Processing}

A measure of $10 \mathrm{~g}$ of dried and ground I. cairica leaves and stems were exhaustively extracted with ethanol (Et) using an ultrasonic bath at $40{ }^{\circ} \mathrm{C}$ for $15 \mathrm{~min}$ for each extraction, and then the extracts were combined and dried using a rotary evaporator with a temperature-controlled bath at $40{ }^{\circ} \mathrm{C}$ under reduced pressure. Subsequently, $100 \mathrm{~g}$ of the stems were extracted and concentrated; once dry, the extract was fractionated using CC with silica gel as the stationary phase and an increasingly polar gradient of He, DCM, Ac, or Me as the mobile phase. The resulting fractions were concentrated to dryness.

\subsection{Monitoring Using TLC and Isolation Using Preparative TLC}

The resulting fractions were evaluated using TLC on silica gel with a fluorescent indicator as the stationary phase, and toluene:ether (1:1) saturated with $10 \%$ acetic acid as the mobile phase [17]. Ultraviolet light was used at $254 \mathrm{~nm}$ and $365 \mathrm{~nm}$ to develop the plates, possible coumarins were revealed by spraying the plates with $10 \%$ potassium hydroxide in ethanol [17].

The preparative TLC technique was performed under the same conditions (stationary phase and mobile phase) as the TLC procedure; however, it used a greater amount of sample because it was designed to isolate the compounds. The bands of interest were scraped, extracted with DCM, and subsequently dried to recover the isolated compounds. The extraction, fractionation, and larvicidal activity assays were performed in quadruplicate to exclude any false positives or negatives throughout the test.

4.4. High-Efficiency Liquid Chromatography with a Diode Array Detector and Mass Spectrometry (HPLC-DAD-MS/MS)

For the HPLC-DAD technique, a Shimadzu system, consisting of a DGU20A5 degasser, LC20AT pump, SPDM20A diode array detector, and a $50 \mu \mathrm{L}$ manual loop injector, was used. The gradient used was $0.1 \%$ trifluoroacetic acid as mobile phase A and methanol as mobile phase $\mathrm{B}$; the run began with $15 \%$ mobile phase A and ended with $100 \%$ mobile phase B in $20 \mathrm{~min}$, with a flow rate of $1 \mathrm{~mL} / \mathrm{min}$, as shown in Table 6. The column used 
was a Phenomenex Luna C18 column $(250 \times 4.6 \mathrm{~mm}, 5 \mathrm{~mm}$ particle size, $100 \AA$ pore size $)$. For the semipreparative HPLC technique, an Agilent Pursuit column $(250 \times 10 \mathrm{~mm}, 10 \mathrm{~mm}$ particle size) was used at a flow rate faster than the analytical flow rate of $4.5 \mathrm{~mL} / \mathrm{min}$. The mass detector was used with the following operating conditions: flow rate $-0.5 \mathrm{~mL} / \mathrm{min}$; polarity-electrospray ionization (ESI)+; carrier gas-30 psi; nebulizer-45 psi; drying gas -55 psi; capillary voltage $-5.5 \mathrm{kV}$; collision gas-10 psi.

Table 6. Gradient used in reverse-phase HPLC for the chromatographic separation of the secondary metabolites present in the crude extracts of I. cairica.

\begin{tabular}{cccc}
\hline Time (min) & Concentration of A & Concentration of B & Flow Rate (mL/min) \\
\hline 0.01 & 85 & 15 & 1.00 \\
\hline 3.00 & 65 & 35 & 1.00 \\
\hline 7.00 & 60 & 40 & 1.00 \\
\hline 10.00 & 55 & 45 & 1.00 \\
\hline 13.00 & 50 & 50 & 1.00 \\
\hline 15.00 & 50 & 50 & 0.50 \\
\hline 16.00 & 50 & 50 & 0.50 \\
\hline 18.00 & 15 & 85 & 0.50 \\
\hline 18.00 & 15 & 85 & 1.25 \\
\hline 19.00 & 0 & 100 & 1.25 \\
\hline 20.00 & 85 & 15 & 1.00 \\
\hline
\end{tabular}

\subsection{Larval Culture}

Eggs of the A. aegypti Rockefeller strain, that is susceptible to insecticides, were stored on filter paper in a dry environment out of direct light under controlled environmental conditions. When larvae were needed, eggs were placed in pans with a sufficient amount of water to assure proper hatching. Conditions were standardized in every batch to avoid larval overcrowding. Proper feeding occurred to ensure healthy and homogeneous larval growth.

\subsection{Bioassay of Larvicidal Activity}

The method used to determine larvicidal activity was described by the World Health Organization in the $\mathrm{WHO} / \mathrm{VBC} / 81.807$ report for the determination of larvicidal activity [25]. Third- and fourth-instar larvae of the A. aegypti Rockefeller strain, susceptible to insecticides, were used. The larvae were maintained in the laboratory without any exposure to known insecticides. The larvae were obtained from eggs hatched simultaneously and raised under the same food and environmental conditions to ensure physiological homogeneity in each assay. In the assays, 4 replicates were used per concentration of metabolite or extract, with 20 larvae each and a total volume of $25 \mathrm{~mL}$. A positive control group treated with temephos and a negative control group treated with water were established. Mortality was determined $24 \mathrm{~h}$ after the start of the assay. The initially evaluated concentrations were $100 \mathrm{ppm}$ for the determination of the $\mathrm{LC}_{50}$ and $\mathrm{LC}_{90}$ values. The CIs were determined for each value.

Author Contributions: Conceptualization, methodology, software, validation, investigation, data curation, visualization, funding acquisition and writing —original draft preparation: V.Á.V., G.R.R. and S.A.V.; Formal analysis resources, V.Á.V.; Writing—review and editing, V.Á.V. and S.A.V.; Supervision: G.R.R., S.A.V.; Project administration resources, V.Á.V. All authors have read and agreed to the published version of the manuscript. 
Funding: The translation and publication of this study were funded by the "Fund to support the dissemination of knowledge generated at National University [Fondo para apoyo a la divulgación del conocimiento generado en la UNA]" according to resolution UNA-VI-RESO-116-2021.

Institutional Review Board Statement: Not applicable.

Informed Consent Statement: Not applicable.

Data Availability Statement: Data supporting reported results are available at victor.alvarez. valverde@una.cr.

Acknowledgments: We thank the Regional Institute for Toxic Substances Research (Instituto Regional de Estudios en Sustancias Tóxicas-IRET) for providing access to the mass spectrometer with which the structures were confirmed.

Conflicts of Interest: The authors have no conflicts of interest to declare.

Sample Availability: Plant samples are available from the authors.

\section{References}

1. Kim, S.I.; Ahn, Y.J. Larvicidal activity of lignans and alkaloid identified in Zanthoxylum piperitum bark toward insecticidesusceptible and wild Culex pipiens pallens and Aedes aegypti. Parasites Vectors 2017, 10, 1-10. [CrossRef] [PubMed]

2. Rey, J.; Lounibos, P. Ecología de Aedes aegypti y Aedes albopictus en América y la transmisión de enfermedades. Biomédica 2015, 35, 1-27. [CrossRef]

3. Patterson, J.; Sammon, M.; Garg, M. Dengue, zika and chikungunya: Emerging arboviruses in the new world. West. J. Emerg. Med. 2016, 17, 671-679. [CrossRef] [PubMed]

4. Ministry of Health of Costa Rica Dengue Cases in 2020 Already Exceed All Cases in 2019. Available online: https://www. ministeriodesalud.go.cr/index.php/vigilancia-de-la-salud/analisis-de-situacion-de-salud (accessed on 7 April 2021).

5. Yu, B.; Luo, J.; Wang, J.; Zhang, D.; Yu, S.; Kong, L. Pentasaccharide resin glycosides from Ipomoea cairica and their cytotoxic activities. Phytochemistry 2013, 95, 421-427. [CrossRef] [PubMed]

6. $\quad$ Ferreira, A.A.; Amaral, F.A.; Duarte, I.D.G.; Oliveira, P.M.; Alves, R.B.; Silveira, D.; Azevedo, A.O.; Raslan, D.S.; Castro, M.S.A. Antinociceptive effect from Ipomoea cairica extract. J. Ethnopharmacol. 2006, 105, 148-153. [CrossRef]

7. Arora, S.; Kumar, D. Shiba Phytochemical, antimicrobial and antioxidant activities of methanol extract of leaves and flowers of Ipomoea Cairica. Int. J. Pharm. Pharm. Sci. 2013, 5, 198-202.

8. Ahbirami, R.; Zuharah, W.F.; Thiagaletchumi, M.; Subramaniam, S.; Sundarasekar, J. Larvicidal efficacy of different plant parts of railway creeper, Ipomoea cairica extract against dengue vector mosquitoes, Aedes albopictus (Diptera: Culicidae) and Aedes aegypti (Diptera: Culicidae). J. Insect Sci. 2014, 14, 180. [CrossRef]

9. Lima, O.; Braz-Filho, R. Dibenzylbutyrolactone lignans and coumarins from Ipomoea cairica. J. Braz. Chem. Soc. 1997, 8, 235-238. [CrossRef]

10. Senthil-Nathan, S. A Review of Resistance Mechanisms of Synthetic Insecticides and Botanicals, Phytochemicals, and Essential Oils as Alternative Larvicidal Agents Against Mosquitoes. Front. Physiol. 2020, 10, 1-21. [CrossRef]

11. Srivastava, D.; Shukla, K. Ipomoea cairica: A medicinal weed with promising health benefits. Int. J. Inf. Res. Rev. 2015, 2, 687-694.

12. Giatropoulos, A.; Kimbaris, A.; Michaelakis, A.; Papachristos, D.P.; Polissiou, M.G.; Emmanouel, N. Chemical composition and assessment of larvicidal and repellent capacity of 14 Lamiaceae essential oils against Aedes albopictus. Parasitol. Res. 2018, 117, 1953-1964. [CrossRef] [PubMed]

13. Hari, I.; Mathew, N. Larvicidal activity of selected plant extracts and their combination against the mosquito vectors Culex quinquefasciatus and Aedes aegypti. Environ. Sci. Pollut. Res. 2018, 25, 9176-9185. [CrossRef] [PubMed]

14. Chellappandian, M.; Vasantha-Srinivasan, P.; Senthil-Nathan, S.; Karthi, S.; Thanigaivel, A.; Ponsankar, A.; Kalaivani, K.; Hunter, W.B. Botanical essential oils and uses as mosquitocides and repellents against dengue. Environ. Int. 2018, 113, 214-230. [CrossRef] [PubMed]

15. Álvarez, V.; Rodríguez, G.; Argüello, S. Insecticidal activity of ethanolic plant extracts on Aedes aegypti larvae. 2022; submitted.

16. Chariandy, C.; Seaforth, C.; Phelps, R.; Pollard, G.; Khambay, B. Screening of medicinal plants from Trinidad and Tobago for antimicrobial and insecticidal properties. J. Ethnopharmacol. 1999, 64, 265-270. [CrossRef]

17. Najafabadi, N.S.; Sahari, M.A.; Barzegar, M.; Hamidi Esfahani, Z. Role of Extraction Conditions in the Recovery of Some Phytochemical Compounds of the Jujube Fruit. J. Agric. Sci. Technol. 2020, 22, 439-451.

18. Meira, M.; da Silva, E.P.; David, J.M.; David, J.P. Review of the genus Ipomoea: Traditional uses, chemistry and biological activities. Braz. J. Pharmacogn. 2012, 22, 682-713. [CrossRef]

19. Hildebert, W.; Sabine, B. Plant Drug Analysis: A Thin Layer Chromatography Atlas; Segunda, Ed.; Springer: New York, NY, USA, 1996; pp. 125-147.

20. Mercolini, L.; Mandrioli, R.; Ferranti, A.; Sorella, V.; Protti, M.; Epifano, F.; Curini, M.; Raggi, M.A. Quantitative evaluation of auraptene and umbelliferone, chemopreventive coumarins in citrus fruits, by HPLC-UV-FL-MS. J. Agric. Food Chem. 2013, 61, 1694-1701. [CrossRef] 
21. Carpinella, M.C.; Ferrayoli, C.G.; Palacios, S.M. Antifungal synergistic effect of scopoletin, a hydroxycoumarin isolated from Melia azedarach L. fruits. J. Agric. Food Chem. 2005, 53, 2922-2927. [CrossRef]

22. Murugan, K.; Mahesh Kumar, P.; Kovendan, K.; Amerasan, D.; Subrmaniam, J.; Hwang, J. Larvicidal, pupicidal, repellent and adulticidal activity of Citrus sinensis orange peel extract against Anopheles stephensi, Aedes aegypti and Culex quinquefasciatus (Diptera: Culicidae). Parasitol. Res. 2012, 111, 1757-1769. [CrossRef]

23. Wang, Z.; Kim, J.-R.R.; Wang, M.; Shu, S.; Ahn, Y.-J.J. Larvicidal activity of Cnidium monnieri fruit coumarins and structurally related compounds against insecticide-susceptible and insecticide-resistant Culex pipiens pallens and Aedes aegypti. Pest. Manag. Sci. 2012, 68, 1041-1047. [CrossRef]

24. Rollinger, J.M.; Hornick, A.; Langer, T.; Stuppner, H.; Prast, H. Acetylcholinesterase inhibitory activity of scopolin and scopoletin discovered by virtual screening of natural products. J. Med. Chem. 2004, 47, 6248-6254. [CrossRef] [PubMed]

25. Patar, A.A.; Hassan, W.R.M.; Yusof, F.Z.M. Acute toxicity of malathion, dichlorvos and temephos in climbing perch (Anabas testudineus). Malaysian Appl. Biol. 2015, 44, 37-42.

26. Costa, M.S.; Santana, A.E.G.; Oliveira, L.L.; Zanuncio, J.C.; Serrão, J.E. Toxicity of squamocin on Aedes aegypti larvae, its predators and human cells. Pest. Manag. Sci. 2017, 73, 636-640. [CrossRef] [PubMed]

27. Miyoshi, H.; Ohshima, M.; Shimada, H.; Akagi, T.; Iwamura, H.; McLaughlin, J.L. Essential structural factors of annonaceous acetogenins as potent inhibitors of mitochondrial complex I. Biochim. Biophys. Acta-Bioenerg. 1998, 1365, 443-452. [CrossRef]

28. Benelli, G.; Pavela, R.; Canale, A.; Cianfaglione, K.; Ciaschetti, G.; Conti, F.; Nicoletti, M.; Senthil-Nathan, S.; Mehlhorn, H.; Maggi, F. Acute larvicidal toxicity of five essential oils (Pinus nigra, Hyssopus officinalis, Satureja montana, Aloysia citrodora and Pelargonium graveolens) against the filariasis vector Culex quinquefasciatus: Synergistic and antagonistic effects. Parasitol. Int. 2017, 66, 166-171. [CrossRef]

29. Andrade-Ochoa, S.; Sánchez-Aldana, D.; Chacón-Vargas, K.F.; Rivera-Chavira, B.E.; Sánchez-Torres, L.E.; Camacho, A.D.; Nogueda-Torres, B.; Nevárez-Moorillón, G.V. Oviposition deterrent and larvicidal and pupaecidal activity of seven essential oils and their major components against Culex quinquefasciatus say (Diptera: Culicidae): Synergism-antagonism effects. Insects 2018, 9, 25. [CrossRef]

30. Pinto, C.C.C.; De Menezes, J.E.S.A.; Melo, D.S.; Feitosa, C.R.S. Chemical Composition and larvicidal activity against Aedes aegypti of essential oils from Croton jacobinenesis Baill. Boletín Latinoam. Caribe Plantas Med. Aromáticas 2016, 15, $122-127$.

31. Silvério, M.R.S.; Espindola, L.S.; Lopes, N.P.; Vieira, P.C. Plant natural products for the control of Aedes aegypti: The main vector of important arboviruses. Molecules 2020, 25, 3484. [CrossRef]

32. De Souza Wuillda, A.C.J.; Martins, R.C.C.; Costa, F.D.N. Larvicidal activity of secondary plant metabolites in aedes aegypti control: An overview of the previous 6 years. Nat. Prod. Commun. 2019, 14, 1934578X19862893. [CrossRef]

33. Mordue(Luntz), A.J.; Nisbet, A.J. Azadirachtin from the neem tree Azadirachta indica: Its action against insects. An. Soc. Entomol. Bras. 2000, 29, 615-632. [CrossRef]

34. Kishore, N.; Mishra, B.; Tiwari, V.; Tripathi, V. A review on natural products with mosquitosidal potentials. Res. Signpost Chall. Scope Nat. Prod. Med. Chem. 2011, 37661, 335-365. 